\title{
Hearing loss and hearing needs in an adult homeless population: a prospective cross-sectional study
}

\author{
Christopher W. Noel MD, Florence Mok MD, Vincent Wu MD, Antoine Eskander MD SM, \\ Christopher M.K.L. Yao MD, Stephen W. Hwang MD MPH, Myrna Lichter MD, Melissa Reekie MSc, \\ Sean Smith MSc, Ian Syrett MSc, Molly Zirkle MD MEd, Vincent Lin MD, John M. Lee MD MSc
}

\section{Abstract}

Background: Given that hearing loss is associated with increased social isolation, reduced earning potential and neurocognitive disease, findings of uncorrected hearing loss in the homeless population have important policy implications. We sought to estimate the prevalence of hearing impairment in an adult homeless population.

Methods: We recruited adult (age $\geq 18 \mathrm{yr}$ ) homeless people across 10 homeless shelters in Toronto between April and June 2018 using a 2-stage sampling technique. Participants were interviewed by 1 interviewer using a modified survey that had been used in previous studies looking at other health needs in homeless populations. A comprehensive head and neck examination and audiometric evaluation were performed in each participant by an otolaryngologist and an audiologist. Descriptive statistics were estimated. Audiometric data were standardized directly for age and sex to facilitate direct comparisons with the general Canadian population.

Results: Of the 132 people invited, 100 (75.8\%) agreed to participate. The median age was 46 (interquartile range [IQR] 37-58) years. The median duration of homelessness was 24 (IQR 6-72) months. Although most participants (78) had some form of extended health care benefits through social assistance, only $22 / 78(28 \%)$ were aware that hearing tests and hearing aids were covered through these programs. After direct standardization for age and sex, the proportions of participants with a speech-frequency and high-frequency hearing loss were $39.5 \%$ (95\% confidence interval $[\mathrm{Cl}] 30.4 \%-49.3 \%)$ and $51.9 \%(95 \% \mathrm{Cl} 42.2 \%-61.4 \%)$, respectively. Nineteen participants were hearing aid candidates, only 1 of whom owned functional hearing aids. Rates of speechfrequency hearing loss $(39.5 \%, 95 \% \mathrm{Cl} 30.4 \%-49.3 \% \mathrm{v} .19 .2 \%, 95 \% \mathrm{Cl} 16.9 \%-21.7 \%)$ and high-frequency hearing loss $(51.9 \%$, $95 \% \mathrm{Cl} 42.2 \%-61.4 \%$ v. $35.5 \%, 95 \% \mathrm{Cl} 33.1 \%-37.7 \%$ ) were substantially higher than in the general Canadian population.

Interpretation: Our results suggest that homeless adults have a high prevalence of hearing impairment, even when living within a system of universal health insurance; awareness of health care benefits through social assistance programs was poor. Results from this study may prompt initiatives surrounding homeless outreach and health screening.

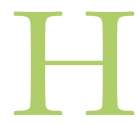

omelessness is an important risk factor for poor health outcomes and represents a growing public health concern. About a quarter of a million Canadians experience homelessness in any given year. ${ }^{1}$ The link between homelessness and health has been previously established, and it is well known that the homeless population is at increased risk for a variety of medical comorbidities including cardiovascular disease, diabetes, hypertension, vision loss and chronic obstructive pulmonary disease..$^{2-9}$ There is also emerging evidence suggesting that the onset of chronic diseases in homeless people may be accelerated. Brown and colleagues ${ }^{10}$ observed that the self-reported rate of geriatric syndromes was higher in a homeless cohort than in a general US population that was, on average, more than 20 years older.
Despite the growing body of knowledge surrounding homelessness and health, the relation between chronic homelessness and hearing status remains unknown. Although various national health surveys have shown a strong association between low socioeconomic status and hearing loss, ${ }^{11-14}$ those studies were geared toward people in

\section{Competing interests: None declared.}

This article has been peer reviewed.

Correspondence to: John Lee, leejo@smh.ca, and Vincent Lin, Vincent.lin@sunnybrook.ca

CMAJ Open 2020. DOI:10.9778/cmajo.20190220 
private dwellings with fixed addresses, and excluded homeless people.

Findings of uncorrected hearing impairment in a homeless population could carry important implications. Hearing loss, like homelessness, has been shown to be strongly correlated with increased social isolation, reduced earning potential and higher rates of neurocognitive disease. ${ }^{15-19}$ Hearing impairment is often treatable, although, as an invisible disability, it is underrecognized and often underdiagnosed.

In this pilot study, we aimed to investigate the prevalence of hearing loss in a sample of people staying in homeless shelters in Toronto and to estimate to what extent those with a hearing impairment were accessing aural rehabilitation.

\section{Methods}

\section{Setting, design and participant selection}

In this prospective cross-sectional study, we used a 2-stage sampling technique to establish the prevalence of hearing impairment among a representative sample of people in homeless shelters in Toronto. Participants were recruited between April and June 2018. We identified all homeless shelters for adults with more than 20 beds in the city. From this list, we randomly selected 10 shelters, with the probability of selection being proportionate to each shelter's nightly housing capacity. We then randomly selected bed numbers within each shelter using simple randomization via a randomnumber generator (random.org). People assigned to those beds were invited to participate in the study. Participants were excluded if they were less than 18 years of age, did not speak English or lacked decisional capacity. ${ }^{20}$ This process continued until 10 participants had been recruited from each shelter.

\section{Definitions}

Consistent with other studies, ${ }^{2,3,21-23}$ we defined homelessness as residence in a homeless shelter for a minimum of 7 consecutive days.

We defined hearing loss as a unilateral or bilateral hearing threshold above $25 \mathrm{~dB}$ in the worse ear, based on 4-frequency pure-tone average across $0.5,1,2$ and $4 \mathrm{kHz}$ ("speechfrequency") and pure-tone average across 3, 4, 6 and $8 \mathrm{kHz}$ ("high-frequency"). Hearing loss thresholds were based on the American Speech-Language-Hearing Association guidelines. $^{24}$

We defined a normal tympanogram as compliance between $0.2 \mathrm{~cm}^{3}$ and $1.8 \mathrm{~cm}^{3}$ with middle ear pressure between -150 and $150 \mathrm{daPa}$ in an equivalent ear canal volume of $0.75-2.0 \mathrm{~cm}^{3}$.

\section{Survey}

All interviews were completed by 1 researcher (C.W.N.), which ensured there were no duplicate participants, using a modified data collection sheet that had been used in previous studies looking at other health needs in homeless populations (Appendix 1, available at www.cmajopen.ca/content/8/1/E199/ suppl/DC1). ${ }^{2-4}$ Demographic characteristics were collected for each participant. To facilitate comparisons with the general Canadian and US populations, some questions in the survey (sections II and III) were identical to those posed in national household surveys (US National Health and Nutrition Examination Survey 1999-2004 [https://www.cdc.gov/nchs/nhanes/] and Canadian Health Measures Survey 2012-2013 ${ }^{25}$ ). For participants with subjective hearing loss, the Hearing Handicap Screening Inventory Questionnaire for Adults, a well-validated 10-item questionnaire ${ }^{26-28}$ (Appendix 1, Section V), was administered. The interviewer also ensured completeness of the records. Participants received a $\$ 10$ gift card after completion of the study.

\section{Audiologic assessment}

All participants underwent an audiologic evaluation conducted by a certified audiologist (M.R. or S.S.) using a portable audiometer (Grason-Stadler GSI 39 Auto Tymp). Participants were brought to a room in the shelter thought by the audiologist to be sufficiently quiet such that it would not affect the results of the evaluation. Air conduction thresholds were determined for either ear, from 0.5 to $8 \mathrm{kHz}$ across an intensity range of -10 to $120 \mathrm{~dB}$.

\section{Statistical analysis}

All statistical analyses were performed with SAS Studio 9.4 (SAS Institute) and Microsoft Excel 16.33. Statistical significance was defined as $p<0.05$. We estimated descriptive and inferential statistics. Audiometric data were standardized directly for age and sex to facilitate direct comparisons with audiometric thresholds collected in a representative sample of the general Canadian population as part of the 2012-2013 Canadian Health Measures Survey. ${ }^{25}$ We used $\chi^{2}$ analysis to assess significant differences between categorical variables. We calculated $95 \%$ confidence intervals (CIs) for proportions using the Wilson methods. ${ }^{29,30}$

\section{Ethics approval}

Ethics approval was obtained from St. Michael's Hospital Research Ethics Board. Written consent was obtained from shelter administrators and individual participants.

\section{Results}

Of the 132 homeless people approached, 100 (75.8\%) agreed to participate in the study. Of the 100, 64 were men. The median age was 46 (interquartile range $37-58$ ) years. The median life duration of homelessness was 24 (interquartile range 6-72) months. Further demographic characteristics are given in Table 1.

Participants had a wide range of medical comorbidities, with the most common self-reported health issues being active smoker (67 participants), depression (36), alcohol abuse (32), other substance abuse (32), hypertension (22) and asthma (19). Eight participants recalled having been assessed and treated by an otolaryngologist in the past: 2 underwent tonsillectomy, 2 had myringotomy and tube insertion, 1 had tympanoplasty, 1 had translabyrinthine excision of a cerebellopontine angle tumour, 1 underwent functional rhinoplasty, and 1 had a deep space neck infection requiring surgical drainage. 


\section{Table 1: Demographic characteristics of homeless participants surveyed}

\begin{tabular}{|c|c|}
\hline Characteristic & $\begin{array}{c}\text { No. of } \\
\text { participants* } \\
n=100\end{array}$ \\
\hline \multicolumn{2}{|l|}{ Sex } \\
\hline Male & 64 \\
\hline Female & 36 \\
\hline Age, yr, median (IQR) & $46(37-58)$ \\
\hline \multicolumn{2}{|l|}{ Age group, yr } \\
\hline 20-39 & 32 \\
\hline $40-49$ & 22 \\
\hline $50-59$ & 26 \\
\hline $60-69$ & 14 \\
\hline $70-79$ & 6 \\
\hline \multicolumn{2}{|l|}{ Length of time spent homeless, yr } \\
\hline$<1$ & 38 \\
\hline $1-5$ & 33 \\
\hline$>5$ & 29 \\
\hline Median (IQR) & $2(0.5-6.0)$ \\
\hline \multicolumn{2}{|l|}{ Ethnicity } \\
\hline White & 57 \\
\hline Black & 35 \\
\hline Aboriginal & 4 \\
\hline East Asian & 2 \\
\hline South Asian & 2 \\
\hline \multicolumn{2}{|l|}{ Marital status } \\
\hline Single & 66 \\
\hline Married/common-law marriage & 9 \\
\hline Divorced, separated or widowed & 24 \\
\hline Declined to answer & 1 \\
\hline \multicolumn{2}{|l|}{ Highest level of education achieved } \\
\hline Elementary school & 1 \\
\hline Junior high school & 8 \\
\hline Some high school & 19 \\
\hline High school graduate & 37 \\
\hline Some college education & 35 \\
\hline \multicolumn{2}{|l|}{ Monthly income, \$ } \\
\hline$<500$ & 45 \\
\hline $500-1000$ & 23 \\
\hline$>1000$ & 22 \\
\hline Declined to answer & 10 \\
\hline $\begin{array}{l}\text { Note: IQR = interquartile range. } \\
{ }^{*} \text { Except where noted otherwise. }\end{array}$ & \\
\hline
\end{tabular}

Most participants (78) had some form of extended health care benefits through social assistance, although only 22 $(28 \%)$ of these participants were aware that hearing tests and hearing aids were covered through these programs.

When asked about risk factors for noise exposure, 59 participants stated that they had worked or lived in an environment where their voice needed to be raised in order to be heard for a minimum of 3 consecutive months. The mean duration of exposure was 8.5 years (range 3 mo to $50 \mathrm{yr}$ ). Of the 59 participants, only $22(37 \%)$ stated that they wore hearing protection consistently.

Thirty-two participants reported at least some difficulty with hearing. Hearing Handicap Screening Inventory Questionnaire for Adults scores suggested that 37 participants experienced no handicap, 44 experienced a mild to moderate handicap, and 19 had a severe handicap. Twenty-two participants reported a hearing or ear-related problem in the previous year, but only $11(50 \%)$ were able to access the required care. Many cited lack of a family doctor, competing interests (e.g. securing housing, seeking employment) and distrust of health care providers as reasons for not seeking care.

Audiometric evaluation showed that 39 participants had a mild speech-frequency hearing loss in at least 1 ear, and 51 had a mild high-frequency hearing loss in at least 1 ear (Table 2). After standardization for age and sex, the proportion of patients with a speech-frequency loss was 39.5\% (95\% CI $30.4 \%-49.3 \%$ ), more than double the prevalence in the general Canadian population $(19.2 \%, 95 \%$ CI $16.9 \%-$ $21.7 \%)$. The proportion with a high-frequency hearing loss was $51.9 \%$ (95\% CI $42.2 \%-61.4 \%$ ), much higher than the rate reported in the general Canadian population $(35.5 \%$, 95\% CI $33.1 \%-37.7 \%$ ).

There was a positive association between prevalence of hearing loss and advanced age: $16 \%$ (95\% CI 7\%-32\%) of participants less than age 39 had a speech-frequency hearing loss, compared to $85 \%$ (95\% CI $64 \%-95 \%$ ) of those aged 60 or more (Table 3). Men were more likely to experience high-frequency hearing loss than women (56\% [95\% CI 46\%-38\%] v. $31 \%$ $[95 \%$ CI 16\%-48\%]). There was no statistically significant association between self-reported noise exposure and hearing loss.

Nineteen participants were hearing aid candidates (had loss of $>25 \mathrm{~dB}$ loss in at least 1 ear, perceived some form of functional disability and were interested in receiving aural rehabilitation). Although 14 of the 19 had benefits to offset the cost, only $2(10 \%)$ owned hearing aids, which were functional in only 1 case.

\section{Interpretation}

Our results suggest that large inequities exist in addressing hearing health needs among homeless people in Toronto. In this study, $39.5 \%$ of a sample of homeless people residing in shelters met the criteria for speech-frequency hearing loss in at least 1 ear, more than double the prevalence in the general Canadian population (19.2\%). ${ }^{25}$ The rate of high-frequency hearing loss, $51.9 \%$, was similarly much higher than that reported in the general Canadian population $(35.5 \%) .{ }^{25}$ 


\begin{tabular}{|c|c|c|c|}
\hline \multirow[b]{2}{*}{$\begin{array}{l}\text { Hearing threshold; } \\
\text { age group, yr }\end{array}$} & \multicolumn{3}{|c|}{ No. (\%) of participants } \\
\hline & $\begin{array}{l}\text { Normal hearing } \\
\quad(\leq 25 \mathrm{~dB})\end{array}$ & $\begin{array}{l}\text { Mild loss } \\
(26-40 \mathrm{~dB})\end{array}$ & $\begin{array}{l}\text { Moderate or worse } \\
\text { loss }(\geq 41 \mathrm{~dB})\end{array}$ \\
\hline \multicolumn{4}{|l|}{ Speech frequency } \\
\hline $20-39$ & $27(84)$ & $4(12)$ & $1(3)$ \\
\hline $40-59$ & $31(65)$ & $11(23)$ & $6(12)$ \\
\hline$\geq 60$ & $3(15)$ & $7(35)$ & $10(50)$ \\
\hline \multicolumn{4}{|l|}{ High frequency } \\
\hline 20-39 & $25(78)$ & $4(12)$ & $3(9)$ \\
\hline $40-59$ & $21(44)$ & $17(35)$ & $10(21)$ \\
\hline$\geq 60$ & $3(15)$ & 7 (35) & $10(50)$ \\
\hline
\end{tabular}

\begin{tabular}{|c|c|c|c|c|}
\hline \multirow[b]{2}{*}{ Characteristic } & \multicolumn{2}{|c|}{ Speech frequency hearing loss, \% $(95 \% \mathrm{Cl})$} & \multicolumn{2}{|c|}{ High frequency hearing loss, $\%(95 \% \mathrm{Cl})$} \\
\hline & Study participants & $\begin{array}{l}\text { General Canadian } \\
\text { population }\end{array}$ & Study participants & $\begin{array}{l}\text { General Canadian } \\
\text { population }\end{array}$ \\
\hline \multicolumn{5}{|l|}{ Sex } \\
\hline Male & $42.2(30.9-54.4)$ & $25.3(20.9-30.4)$ & $56.2(44.1-67.7)$ & 41.2. $(36.5-46.0)$ \\
\hline Female & $27.8(15.8-44.0)$ & $13.1(11.0-15.6)$ & $30.6(18.0-46.9)$ & $29.7(24.9-35.0)$ \\
\hline \multicolumn{5}{|l|}{ Age, yr } \\
\hline $20-39$ & $15.6(6.9-31.8)$ & $7.1(4.2-11.7)$ & $21.9(11.0-38.8)$ & $8.0(5.3-11.9)$ \\
\hline $40-49$ & $31.8(16.3-52.7)$ & $10.1(6.6-15.2)$ & $50.0(30.7-69.3)$ & $21.3(14.6-31.4)$ \\
\hline $50-59$ & $34.6(19.4-3.8)$ & $19.9(14.1-27.3)$ & $57.7(39.0-74.5)$ & $49.1(39.9-58.3)$ \\
\hline $60-69$ & $92.8(68.5-98.7)$ & $38.3(34.4-42.3)$ & $92.9(68.5-98.7)$ & $74.1(70.1-77.7)$ \\
\hline $70-79$ & $66.7(30.0-90.3)$ & $65.0(56.4-72.7)$ & $1.0(61.0-100.0)$ & $93.8(88.1-96.8)$ \\
\hline \multicolumn{5}{|l|}{ Noise exposure } \\
\hline No & $36.6(23.6-51.9)$ & - & $46.3(32.1-61.3)$ & - \\
\hline Yes & $40.7(29.1-53.4)$ & - & $57.6(44.9-69.4)$ & - \\
\hline Total & $39.5(30.4-49.3)^{\star}$ & $19.2(16.9-21.7)$ & $51.9(42.2-61.4)^{*}$ & 35.5 (33.1-37.7) \\
\hline
\end{tabular}

Most of the limited information surrounding hearing needs of homeless people has been generated from studies conducted in the United States. One study focusing on geriatric syndromes in a group of homeless people aged 40-59 indicated self-reported hearing impairment in $29.7 \% .{ }^{10}$ Although that work provides a glimpse into the problem, self-report methods are known to underestimate rates of hearing loss. ${ }^{31}$ Another study of 132 homeless people showed that $34.9 \%$ had speechfrequency hearing loss. ${ }^{32}$ However, that work was limited by its retrospective design and used a convenience sampling technique. Our work builds on these studies through the incorporation of a 2-stage sampling technique and an assessment by an otolaryngologist in addition to audiometric evaluation.
Although the link between homelessness and hearing impairment has not been investigated adequately, the correlation between hearing loss, income and unemployment has been documented in international studies. ${ }^{11-13}$ Data from the US National Health and Nutrition Examination Survey showed that people with hearing loss were 1.58 times more likely to be low income earners and 1.98 times more likely to be unemployed than people with normal hearing. ${ }^{14}$

Whether it is low socioeconomic status that drives hearing loss or vice versa continues to be a source of debate. Hearingimpaired people have been shown to report significantly less control in the workplace, higher effort during listening and more frequent sick leave compared to normal-hearing 
colleagues. ${ }^{33}$ However, low socioeconomic status may drive the development of hearing loss, with less-educated people pursuing activities that increase their exposure to loud noise. ${ }^{34}$ Consistent with the latter theory, $59 \%$ of our participants reported prolonged noise exposure in the workplace. Given the nature of this descriptive study, our ability to explore the nature of the relation between chronic homelessness and hearing loss was limited.

About one-fifth of our participants were determined to be able to benefit from hearing aid use. However, only 2 owned hearing aids, which were functional in only 1 case.

We believe that underuse of hearing aids in this population is multifactorial. One previously cited reason for underuse is the prohibitive cost of obtaining a hearing aid. Mizutari and colleagues $^{35}$ reported lower hearing aid ownership in countries where hearing aids are not covered by public health insurance than in countries with such coverage. For patients covered under provincial social assistance programs, such as Ontario Works and the Ontario Disability Support Program, essential hearing aid costs are covered. The Ontario Disability Support Program provides full coverage of mid-level hearing aids in Toronto. ${ }^{36}$ For patients with Ontario Works, the maximum provincial contribution is $\$ 1600$ toward a pair of hearing aids. Combined with the $\$ 1000$ Assisted Devices Program subsidy, this results in a maximum contribution of $\$ 2600$ per pair of hearing aids. ${ }^{37}$ At St. Michaels Hospital, in Toronto, the dispensing fee is lowered to accommodate lower-income people; however, this practice is not adopted universally in Ontario.

Although 14 of our 19 participants who were hearing aid candidates were eligible for free essential hearing aid technology through the Ontario Disability Support Program or Ontario Works, the majority were unaware of the availability of these benefits. In addition, homeless people may face challenges of keeping a hearing aid clean, dry and charged while navigating the shelter system.

Although rates of hearing aid underuse are similar among the homeless population and the general public, ${ }^{25}$ greater efforts should be provided to improve aural rehabilitation in homeless people who have hearing impairment. As noted, homeless people experience earlier onset of geriatric syndromes ${ }^{10}$ and may be negatively affected in terms of employment and job security owing to hearing loss. We believe that homeless people with hearing loss may gain substantial benefits from being aided.

Currently, there exist mobile screening programs for vision health in the homeless population in Toronto, and it may be possible to initiate hearing screening alongside these preexisting programs. Information and education could also be provided to shelters and homeless people with hearing concerns so as to increase knowledge, thereby decreasing the barriers to accessing health care resources such as hearing aids.

\section{Limitations}

The results of this study must be interpreted in the context of the study design. Although Toronto shelters are known to represent the majority $(72.2 \%)$ of the Toronto homeless pop- ulation, there is a substantial cohort of people who do not access shelter services and would have been missed. ${ }^{7}$ Second, the audiologic assessment was performed within a quiet area of the shelter with a portable audiometer instead of within a sound booth. Although this may have affected the accuracy of the audiometry results, for evaluation of hearing loss greater than $25 \mathrm{~dB}$, testing results generated within a quiet area have been shown to be not significantly different from those generated in a sound booth. ${ }^{38}$ Third, data for a representative sample of Torontonians are not readily available; however, we would not expect the prevalence of hearing impairment to differ substantially from national estimates. Finally, the data were drawn from an urban homeless population in a large Canadian city and may not reflect the experience of other Canadian centres or be generalizable to homeless populations who live outside systems of universal health insurance.

\section{Conclusion}

Within the homeless population in Toronto, $40 \%$ and $52 \%$ of the surveyed participants met the criteria for speechfrequency and high-frequency hearing loss, respectively. These rates are significantly higher than the rates reported for the general Canadian population. Although social assistance programs are in place to support aural rehabilitation, awareness and use of these health care benefits among our participants was low. Results from this study may prompt initiatives surrounding homeless outreach and health screening.

\section{References}

1. Gaetz S, Gulliver T, Richter T. The state of homelessness in Canada 2014 Toronto: The Canadian Observatory on Homelessness/Homeless Hub; 2014.

2. Noel CW, Fung H, Srivastava R, et al. Visual impairment and unmet eye care needs among homeless adults in a Canadian city. 7AMA Ophthalmol 2015;133: 455-60.

3. Noel CW, Srivastava R, Lo R, et al. Unmet eye care needs among a homeless youth population. Can $\mathcal{F}$ Ophthalmol 2016;51:180-4.

4. Jiang S, Mikhail M, Slomovic J, et al. Prevalence and impact of eye disease in an urban homeless and marginally housed population. Can 7 Ophthalmol 2020; 55:76-81.

5. Hwang SW. Homelessness and health. CMA7 2001;164:229-33.

6. Hwang SW, Bugeja AL. Barriers to appropriate diabetes management among homeless people in Toronto. CMA7 2000;163:161-5.

7. Hwang SW, Martin RE, Tolomiczenko GS, et al. The relationship between housing conditions and health status of rooming house residents in Toronto. Can 7 Public Health 2003;94:436-40.

8. Gelberg L, Linn LS. Assessing the physical health of homeless adults. FAMA 1989;262:1973-9.

9. Kushel MB, Vittinghoff E, Haas JS. Factors associated with the health care utilization of homeless persons. 7AMA 2001;285:200-6.

10. Brown RT, Kiely DK, Bharel M, et al. Geriatric syndromes in older homeless adults. 7 Gen Intern Med 2012;27:16-22.

11. Helvik AS, Krokstad S, Tambs K. Socioeconomic inequalities in hearing loss in a healthy population sample: the HUNT Study. Am 7 Public Health 2009;99: 1376-8.

12. Hasson D, Theorell T, Westerlund H, et al. Prevalence and characteristics of hearing problems in a working and non-working Swedish population. 7 Epidemiol Community Health 2010;64:453-60.

13. Järvelin MR, Mäki-Torkko E, Sorri MJ, et al. Effect of hearing impairment on educational outcomes and employment up to the age of 25 years in northern Finland. Br 7 Audiol 1997;31:165-75.

14. Emmett SD, Francis HW. The socioeconomic impact of hearing loss in U.S. adults. Otol Neurotol 2015;36:545-50.

15. Dalton DS, Cruickshanks KJ, Klein BE, et al. The impact of hearing loss on quality of life in older adults. Gerontologist 2003;43:661-8.

16. Weinstein BE, Ventry IM. Hearing impairment and social isolation in the elderly. 7 Speech Hear Res 1982;25:593-9.

17. Centers for Disease Control and Prevention. Economic costs associated with mental retardation, cerebral palsy, hearing loss, and vision impairment United States, 2003. MMWR Morb Mortal Wkly Rep 2004;53:57-9. 
18. Uhlmann RF, Larson EB, Rees TS, et al. Relationship of hearing impairment to dementia and cognitive dysfunction in older adults. 7AMA 1989;261:1916-9.

19. Mick P, Kawachi I, Lin FR. The association between hearing loss and social isolation in older adults. Otolaryngol Head Neck Surg 2014;150:378-84.

20. Etchells E. Aid to capacity evaluation (ACE). Toronto: Joint Centre for Bioethics; modified 2015.

21. Grinman MN, Chiu S, Redelmeier DA, et al. Drug problems among homeless individuals in Toronto, Canada: prevalence, drugs of choice, and relation to health status. BMC Public Health 2010;10:94.

22. Figueiredo R, Dempster L, Quiñonez C, et al. Emergency department use for dental problems among homeless individuals: a population-based cohort study. 7 Health Care Poor Underserved 2016;27:860-8.

23. Figueiredo RL, Hwang SW, Quiñonez C. Dental health of homeless adults in Toronto, Canada. 7 Public Health Dent 2013;73:74-8.

24. Guidelines for audiologic screening. Rockville (MD): American Speech-LanguageHearing Association; 1997.

25. Feder K, Michaud D, Ramage-Morin P, et al. Prevalence of hearing loss among Canadians aged 20 to 79: audiometric results from the 2012/2013 Canadian Health Measures Survey. Health Rep 2015;26:18-25.

26. Newman CW, Weinstein BE, Jacobson GP, et al. The Hearing Handicap Inventory for Adults: psychometric adequacy and audiometric correlates. Ear Hear 1990;11:430-3.

27. Newman CW, Weinstein BE, Jacobson GP, et al. Test-retest reliability of the Hearing Handicap Inventory for Adults. Ear Hear 1991;12:355-7.

28. Aiello CP, de Lima II, Ferrari DV. Validity and reliability of the Hearing Handicap Inventory for Adults. Braz 7 Otorhinolaryngol 2011;77:432-8.

29. Wilson EB. Probable inference, the law of succession, and statistical inference. 7 Am Stat Assoc 1927;22:209-12.

30. Newcombe RG. Two-sided confidence intervals for the single proportion: comparison of seven methods. Stat Med 1998;17:857-72.

31. Nondahl DM, Cruickshanks KJ, Wiley TL, et al. Accuracy of self-reported hearing loss. Audiology 1998;37:295-301.

32. Saccone PA, Steiger JR. Hearing handicap among adult residents of an urban homeless shelter. 7 Health Care Poor Underserved 2007;18:161-72.

33. Kramer SE, Kapteyn TS, Houtgast T. Occupational performance: comparing normally-hearing and hearing-impaired employees using the Amsterdam Checklist for Hearing and Work. Int 7 Audiol 2006;45:503-12.

34. Vogel I, Verschuure H, van der Ploeg CP, et al. Adolescents and MP3 players: too many risks, too few precautions. Pediatrics 2009;123:e953-8.

35. Mizutari K, Michikawa T, Saito H, et al. Age-related hearing loss and the factors determining continued usage of hearing aids among elderly communitydwelling residents. PLoS One 2013;8:e73622.

36. Ontario Disability Support Program — income support. Toronto: Ontario Ministry of Children, Community and Social Services; 2017. Available: https:// www.mcss.gov.on.ca/en/mcss/programs/social/directives/odsp/is/9_11_ODSP _ISDirectives.aspx (accessed 2020 Feb. 6).

37. Medical supplies and devices. Toronto: City of Toronto. Available: www. toronto.ca/community-people/employment-social-support/health-support/ medical-supplies-and-devices/ (accessed 2020 Feb. 6).
38. Maclennan-Smith F, Swanepoel DW, Hall JW 3rd. Validity of diagnostic pure-tone audiometry without a sound-treated environment in older adults. Int F Audiol 2013;52:66-73.

Affiliations: Department of Otolaryngology - Head and Neck Surgery (Noel, Mok, Wu, Eskander, Yao, Zirkle, Lin), University of Toronto; Institute of Health Policy, Management and Evaluation (Noel), Dalla Lana School of Public Health, University of Toronto; Department of Otolaryngology - Head \& Neck Surgery (Eskander, Syrett, Lin), Sunnybrook Health Sciences Centre; Li Ka Shing Knowledge Institute (Hwang, Lee); Division of General Internal Medicine (Hwang), Department of Medicine, University of Toronto; Departments of Ophthalmology (Lichter), Audiology (Reekie, Smith) and Otolaryngology - Head \& Neck Surgery (Zirkle, Lee), St. Michael's Hospital, Toronto, Ont.

Contributors: Christopher Yao, Molly Zirkle, Vincent Lin and John Lee supervised the project. Vincent Lin and John Lee are senior coauthors. Christopher Noel, Florence Mok, Vincent Wu, Antoine Eskander, Christopher Yao, Stephen Hwang, Ian Syrett, Vincent Lin and John Lee contributed to the study conceptualization. Christopher Noel, Florence Mok, Stephen Hwang, Myrna Lichter, Melissa Reekie and Sean Smith contributed to the study design. Christopher Noel, Melissa Reekie and Sean Smith acquired the data. Christopher Noel and Antoine Eskander analyzed the data. Christopher Noel, Antoine Eskander, Stephen Hwang, John Lee and Vincent Lin interpreted the data. Christopher Noel, Florence Mok and Vincent Wu drafted the manuscript. Christopher Noel, Florence Mok, Vincent $\mathrm{Wu}$, Antoine Eskander, Christopher Yao, Stephen Hwang, Myrna Lichter, Molly Zirkle, Vincent Lin and John Lee revised the manuscript critically for important intellectual content. All of the authors approved the final version to be published and agreed to be accountable for all aspects of the work.

Funding: This work was supported through a Harry Barberian Scholarship Fund award and a Head and Neck Cancer Alliance/American Head and Neck Society International Outreach Cancer Prevention award.

Acknowledgments: The authors thank Katya Feder, Research Scientist, Health Canada, and Leonora Marro, Senior Biostatistician, Health Canada, for supplying the reference audiometric data.

Supplemental information: For reviewer comments and the original submission of this manuscript, please see www.cmajopen.ca/content/8/1/ E199/suppl/DC1. 